\title{
AS COMPETÊNCIAS DOS ASSISTENTES EM ADMINISTRAÇÃO NO SERVIÇO PÚBLICO FEDERAL: UM ESTUDO DE CASO NO IFTM
}

THE ADMINISTRATION ASSISTANTS' COMPETENCES IN THE FEDERAL PUBLIC SERVICE: A STUDY IN IFTM

Christiane Alves Calheiros Sakamoto UFU - Universidade Federal de Uberlândia christiane@iftm.edu.br

Bruno Freitas Ferreira UFU - Universidade Federal de Uberlândia brunoffer@hotmail.com

Claudio Gomide Zacharias UFU - Universidade Federal de Uberlândia claudio.zacharias@gmail.com

Juliana Cristina da Silva UFU - Universidade Federal de Uberlândia julianacris23@hotmail.com

Patrícia Alves UFU - Universidade Federal de Uberlândia patyalves76@hotmail.com

Henrique Geraldo Rodrigues UFU - Universidade Federal de Uberlândia / Mackenzie - SP

Lucas Borges Kappel UNIUBE - Universidade de Uberaba / IFTM - Instituto Federal do Triângulo Mineiro lucaskappel@yahoo.com.br

Submissão: $23 / 10 / 2013$

Aprovação: 18/11/2014 


\title{
RESUMO
}

O presente trabalho tem como objetivo identificar as competências dos assistentes em administração (AAs) alocados na reitoria do Instituto Federal de Educação, Ciência e Tecnologia do Triângulo Mineiro (IFTM) por meio da análise da viabilidade do uso da gestão por competências. O estudo identifica, por intermédio de uma pesquisa qualitativa, os recursos de competência e atributos associados à pessoa como o CHA (conhecimento, as habilidades e as atitudes) destes profissionais. Para a obtenção de dados utilizou-se a pesquisa documental e foi aplicado um questionário, com questões fechadas, elaborado por intermédio da realização de dois grupos focais; os dados foram analisados mediante técnica de análise de conteúdo (BARDIN, 1977). Observou-se que as competências "habilidades" e "atitudes" são as que possuem maior predominância e a "conhecimento" precisa ser melhorada e ampliada.

Palavras-chave: Competências. Assistente. Conhecimento. Habilidade. Atitude.

\begin{abstract}
This paper aims to identify competences of administration assistant's (AAs) allocated in the rectory of the Instituto Federal de Educação, Ciência e Tecnologia do Triângulo Mineiro (IFTM) by analyzing the feasibility of using management competences. The study identifies, through a qualitative research, the resources of competence and attributes associated with the person as the KKA (knowledge, know-how and attitudes) of these professionals. To obtain data used to document research and applied a questionnaire with closed questions, elaborated through the completion of two focus groups, data were analyzed using content analysis technique (BARDIN, 1977). It was observed that the competencies "skills" and "attitudes" are those that have a higher prevalence and the "knowledge" must be improved and expanded.
\end{abstract}

Keywords: Competences. Assistant. Knowledge. Know-how. Attitude. 


\section{Introdução}

Dentro ou fora das organizações, estudos sobre o comportamento humano se apresentam como uma das áreas mais complexas para a pesquisa. O nível de motivação e satisfação das pessoas está entre as variáveis causais mais importantes dos aspectos comportamentais do ser humano, sendo que esses aspectos incidem diretamente no seu desempenho no trabalho (AFFONSO; ROCHA, 2010).

Diante das mudanças no meio organizacional, torna-se uma necessidade o aperfeiçoamento e a implantação de novas práticas de gestão de pessoas, para a aquisição de novas capacitações e conhecimentos, a fim de transformar estes em um diferencial competitivo. A gestão por competências mostra-se como um meio de aproximar os objetivos individuais e os organizacionais, analisando o perfil do profissional e o alinhando às necessidades de cada cargo, elevando-se assim o nível de satisfação pessoal, melhorando o desempenho dos profissionais e o da organização (GRANDO, 2009).

O Decreto $\mathrm{n}^{\circ}$ 5.707, de 23 de fevereiro de 2006, da Presidência da República, define que todas as instituições públicas devem adotar um novo modelo de Gestão de Pessoas baseado na gestão por competências (BRASIL, 2006), com o objetivo de adequar as competências requeridas dos servidores aos objetivos profissionais, melhorando assim a qualidade da prestação dos serviços públicos. No entanto, para que a implantação desse novo modelo de gestão não se torne apenas o cumprimento de uma diretriz, é necessário que as instituições realmente consolidem a gestão por competências como uma cultura de autodesenvolvimento para todos os seus servidores, procurando quebrar um paradigma no que tange os seus modelos tradicionais.

Esse paradigma está relacionado com o reconhecimento de habilidades e atitudes, além dos conhecimentos técnicos, para se inserir o servidor em cargos e funções mais adequadas, pois o desempenho esperado do funcionário corresponde ao cumprimento das atribuições definidas pela organização.

Outra questão diz respeito sobre qual a melhor maneira de atingir a competência gerencial enquanto capacidade de mobilizar, integrar e colocar em ação recursos de competência (conhecimentos, habilidades, atitudes).

Definir as competências para os servidores ocupantes do cargo assistente em administração (AA) da reitoria do IFTM - Instituto Federal de Educação, Ciência e Tecnologia do Triângulo Mineiro está relacionado à necessidade de estabelecer um ambiente organizacional inovador que incentive e reconheça o pensamento estratégico, criativo, 
autônomo e responsável. Assim, se faz importante conhecer as atividades executadas por diferentes tipos de servidores para saber quais as necessidades de formação e capacitação destes.

Neste caso, a gestão por competência é relevante porque oferece uma alternativa eficaz para o preenchimento de cargos e funções, visando ao desenvolvimento de competências individuais para a realização de suas atribuições e responsabilidades; estas competências são entendidas por alguns teóricos da administração como conhecimentos, habilidades e atitudes - CHA (DUTRA et al., 2001). Dessa forma os servidores devem possuir habilidades e atitudes compatíveis com o posto a ser ocupado para que tenham um melhor desempenho de suas atribuições, proporcionando assim serviços de melhor qualidade para os cidadãos.

Sendo assim, este trabalho tem por objetivo identificar as competências do cargo de AA da reitoria do IFTM, proporcionando uma análise da consonância destas competências aos objetivos da organização e às atribuições do cargo e, consequentemente, analisar a viabilidade do uso da gestão por competências no IFTM.

\section{Referencial teórico}

Esta etapa do trabalho foi dividida em quatro subitens: definição e características das competências (1), gestão por competências (2), relação da gestão de competências com o desempenho de organizações públicas (3) e mapeamento das competências (4).

\subsection{Definição e características das competências}

Competência é uma palavra do senso comum, com o significado de pessoa qualificada para desempenhar determinada tarefa ou função. No mundo do trabalho e acadêmico ela vem assumindo diversos significados ligados aos seus componentes como conhecimentos, habilidades e atitudes (DUTRA et al., 2001). Com a emergência da gestão por competências, ampla discussão tem sido feita em torno do conceito de competência, suas dimensões e implicações.

No fim da Idade Média, o termo competência era associado à linguagem jurídica e definido como faculdade atribuída a alguém ou a uma instituição para apreciar e julgar certas questões. Por extensão, o conceito de competência veio designar reconhecimento social sobre a capacidade de alguém ter domínio a respeito de determinado assunto (PIRES, 2005). 
Desde então, vários pesquisadores do tema competências o vem estudando por gerações, definindo novos conceitos, exemplificando estas em cada área específica e propondo novidades em sua análise; Munck, Munck e de Souza (2013), por exemplo, propuseram uma lógica de acontecimento simultâneo entre a competência individual e a competência organizacional.

Picchiai (2011) aplicou as competências organizacionais, gerenciais e individuais ao setor público; V. L. F. da Silva (2011) também atuou no setor público, identificando as competências individuais relevantes para o exercício do cargo de chefe de gabinete, no Superior Tribunal de Justiça. Santos (2012) também estudou o setor público, articulando competências entre as organizacionais e as individuais. Já M. R. P. da Silva (2014) estudou as competências dos alunos do curso de administração da UEPB em relação às ditas “necessárias" pela sociedade.

Na tentativa de uma definição para competência, Gilbert (1978) destaca que ela se expressa em razão do desempenho ou comportamento da pessoa no trabalho, enquanto Durand (2006) dá ênfase aos elementos que constituem a competência, ou seja, aos conhecimentos, as habilidades e as atitudes da pessoa.

Zarifian (2001) define competência como a capacidade do indivíduo de tomar a iniciativa, de ir além do que está prescrito, de compreender e dominar novas situações com as quais pode se deparar no trabalho, e de assumir responsabilidade sobre elas. Para o autor, um indivíduo competente possui um entendimento prático de situações, baseado em conhecimentos adquiridos em experiências anteriores. Possui também a capacidade de mobilizar uma rede de autores, e fazer com que eles compartilhem ações e responsabilidades em torno das mesmas situações.

A competência ainda pode ser vista como a capacidade de entrega da pessoa e, também, como o conjunto de qualificações que a pessoa possui para entregar (DUTRA, 2002). As pessoas entregam o que a organização espera ou necessita de diferentes formas, porque são diferentes na forma como articulam seus conhecimentos, habilidades e atitudes com o contexto ambiental. Portanto, ao definir o que se espera que as pessoas entreguem para a organização, percebe-se que elas o farão por diferentes caminhos. Há pessoas que entregarão o que a empresa espera, dando ênfase às suas habilidades de relacionamento interpessoal, e outras que farão suas entregas dando ênfase às suas habilidades técnicas. Ambas entregarão o esperado, porém de formas diferentes. Essa diversidade é fundamental para a organização, pois, mediante ela, a empresa vai aprendendo diferentes formas de obter sucesso e competitividade (DUTRA, 2002). 
Para Le Boterf (2003) a competência não é um estado, mas uma ação que resulta da combinação de recursos pessoais (conhecimentos, habilidades, qualidades, experiências, capacidades cognitivas, recursos emocionais etc.) e recursos do meio (tecnologia, banco de dados, livros, relacionamentos etc.). Nos recursos do meio, o indivíduo pode buscar complementos para os seus recursos pessoais, quando não possuir todos os saberes que necessita para realizar sua ação competente. A competência consiste em saber combinar esses recursos para produzir uma ação competente. "O saber combinatório está no centro de todas as competências" (LE BOTERF, 2003, p. 12).

Fleury e Fleury (2004) definem competências como um saber agir responsável e reconhecido, que implica mobilizar, integrar, transferir conhecimentos, recursos, habilidades que agregam valor econômico à organização e valor social ao indivíduo.

Ruas (2005) amplia a discussão sobre as competências, comparando-as com a noção de capacidades. Ele esclarece que as capacidades são partes integrantes da noção de competências, mas não representam todo o conceito. A competência só irá existir em um contexto específico, quando as capacidades serão mobilizadas (com determinados recursos daquele contexto) para efetuar uma determinada entrega (objetivos da mobilização das capacidades). Apenas a partir da avaliação da entrega, comparada com os objetivos propostos, é que poderá ser avaliado se existiu ou não a competência.

Nota-se, portanto, que o conceito de competência pode se apresentar na fronteira de diferentes disciplinas como a pedagogia, a sociologia, a psicologia, a economia, a administração, a ergonomia (ARAÚJO, 1999), e mostra-se como um modo de repensar as organizações e os indivíduos que as compõem e pode ser relacionada de modo geral no contexto organizacional e no contexto individual como se segue neste.

A competência no contexto organizacional se desenvolve a partir da perspectiva do indivíduo. Para McClelland (1973) a competência é uma característica subjacente a uma pessoa que pode ser relacionada com desempenho superior na realização de uma tarefa ou em determinada situação. $\mathrm{O}$ autor diferenciava competência de aptidões, que seria um talento natural da pessoa, que pode vir a ser aprimorado; competência de habilidades, que seriam a demonstração de um talento particular na prática; e competência de conhecimentos, o que a pessoa precisa saber para desempenhar uma tarefa.

Nesse sentido, ressalta-se que as competências individuais não se reduzem apenas a um conhecimento específico e nem se limitam a conhecimentos teóricos e empíricos detidos pelo indivíduo. Segundo Zarifian (1999), a competência é a inteligência prática para situações que se apoiam sobre os conhecimentos adquiridos e que ganham força conforme as situações 
ganham complexidade. É um saber agir com responsabilidade, o que implica saber mobilizar, integrar e transferir conhecimentos, recursos e habilidades, num contexto profissional determinado.

A competência individual pode ser definida como a combinação de recursos por parte do indivíduo, dentro do ambiente de trabalho, decorrente da aplicação conjunta de conhecimentos, habilidades e atitudes, que representam os três recursos ou dimensões da competência (COELHO; FUERTH, 2009), de acordo com o mostrado na Figura 1; este é o conceito que orienta o estudo apresentado. Nesse sentido, pode-se constatar que a noção de competência individual envolve diretamente o indivíduo inserido em sua equipe de trabalho, por intermédio de sua atividade prática, uma vez que sua rotina diária implica um saber aprender constante.

Figura 1 - C. H. A. - Diagrama explicativo dos conhecimentos, habilidades e atitudes

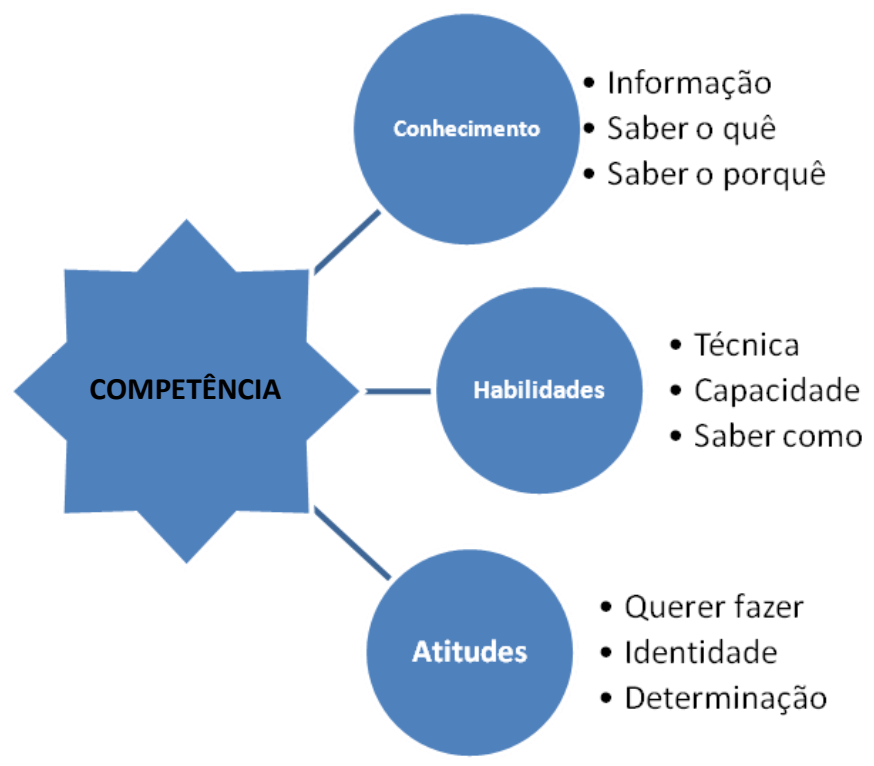

Fonte: Adaptado de Coelho e Fuerth (2009).

Já para Hamel e Prahalad (1990), as competências nas organizações podem ser caracterizadas como a contribuição das pessoas para a capacidade da organização de interagir com seu ambiente, mantendo ou ampliando suas vantagens competitivas. As competências organizacionais, por sua vez, mostram-se como a soma do aprendizado de todo o conjunto de habilidades, conhecimentos, know-how tecnológico e resultados dos processos decisórios da organização. Constitui-se uma fonte de vantagem competitiva, porque deve ser única, deve contribuir para o valor percebido pelo cliente e não deve ser facilmente copiada pela concorrência (FLEURY; FLEURY, 2001).

As informações que um indivíduo reconhece e assimila podem ser entendidas como o seu conhecimento adquirido, que lhe permitem entender o mundo; referem-se, ainda, 
ao saber que a pessoa acumulou ao longo da vida (PIRES, 2005). O conhecimento também pode ser entendido, segundo Pires (2005), como o conjunto de informações reconhecidas e integradas pelo indivíduo dentro de um esquema preexistente, causando impacto sobre seu julgamento ou comportamento.

A habilidade, por sua vez, está relacionada ao saber como fazer algo, à capacidade de fazer uso produtivo do conhecimento, ou seja, de utilizar o conhecimento em uma ação. A definição operacional mais comum sobre a habilidade é a de que o indivíduo pode buscar, em suas experiências anteriores, conhecimentos, sejam eles fatos, princípios ou técnicas, para examinar e solucionar um determinado problema (BRANDÃO; BORGES-ANDRADE, 2008).

A terceira dimensão que integra a definição da competência refere-se aos aspectos sociais e afetivos relacionados ao trabalho. A atitude das pessoas está relacionada às preferências por alguns tipos de atividades, mostrando interesse por certos eventos mais que por outros, sua predisposição em relação à adoção de uma ação específica. A atitude está ligada ao sentimento, à emoção ou a um grau de aceitação ou rejeição da pessoa em relação aos outros, a objetos ou às situações. Portanto, por analogia, a atitude refere-se ao "querer fazer” ou mesmo o "desejar" (BRANDÃO, 2007).

A atitude também pode ser entendida como um componente da motivação intrínseca - aquela relacionada ao desejo, à disposição ou à satisfação pessoal do indivíduo pelo trabalho que realiza, sendo a motivação um importante impulsor do comportamento no trabalho. A atitude parece constituir o fator motivacional, visto que influencia a tendência de a pessoa adotar determinado comportamento.

A partir das várias definições de competências e suas características, é possível delinear os diferentes modelos de gestão de pessoas baseado em competências, especificados no próximo subitem.

\subsection{A gestão por competências}

Diante da globalização, a qual resulta em ambientes com diversos desafios e obstáculos nos quais a adaptação contínua é requerida, tanto para as organizações como para os seus profissionais, se desenvolveu o Modelo de Gestão de Pessoas baseado em competências. Nele, os profissionais são vistos não apenas como especialistas técnicos em determinada área, mas como verdadeiros talentos a serem continuamente aperfeiçoados, de 
forma a desenvolverem todas as suas competências para o seu sucesso como indivíduo e para a organização (DUTRA; HIPÓLITO; SILVA, 2000).

Para Carbone, Brandão e Leite (2005), o modelo de gestão por competências pressupõe que a posse de conhecimentos e competências pela organização faz com que ela ganhe vantagem competitiva. Além disso, a gestão por competências tem como finalidade alocar o profissional em um setor, cargo ou função mais apropriado ao seu perfil, considerando todas as suas competências em conjunto, seus conhecimentos técnicos, suas habilidades e suas atitudes.

Um modelo de competência é normalmente uma descrição narrativa de competências ocupacionais para um grupo identificável, como uma categoria ocupacional, um departamento ou uma ocupação. Ele distingue performances exemplares (best in class) de outras performances (ROTHWELL; LINDHOLM, 1999). Neste sentido, segundo Fernandes e Fleury (2007), são identificadas quatro gerações na evolução dos modelos de gestão por competências: a visão comportamental (1), a competência como input (2), a incorporação da complexidade (3) e a visão abrangente (4).

$\mathrm{Na}$ visão comportamental existe a proposta de identificar tipos ideais de profissionais bem sucedidos, levantar inventários de competências e níveis de conhecimento no exercício de competências. Na competência como input definem-se as competências necessárias a agrupamentos de cargos, algumas genéricas e outras específicas. A terceira geração incorpora o conceito de complexidade, onde são escolhidas competências e, logo após, cada competência é descrita no seu nível de complexidade. A visão abrangente engloba conceitos de competência, complexidade, espaço ocupacional e agregação de valor como referenciais para organizar as práticas de recursos humanos (FERNANDES; FLEURY, 2007).

Assim, devido a sua complexidade, ainda existem incertezas em relação à maneira como se deve aplicar o modelo de gestão de competência no setor público (AMARAL, 2008), foco do próximo subitem.

\subsection{Competências e desempenho de organizações públicas}

O Decreto $\mathrm{n}^{\circ}$ 5.707, de 23 de fevereiro de 2006, da Presidência da República, definiu que todas as instituições públicas devem modernizar a atuação da área de recursos humanos por meio da implantação de um modelo de gestão de pessoas com foco em competências. Isso significa que as instituições públicas devem mudar seu modelo de gestão 
de recursos humanos como um todo, implementando mudanças na postura dos servidores (BRASIL, 2006).

Para definir seu próprio modelo de gestão de pessoas baseado em competências, as especificidades culturais e atribuições particulares de cada organização pública devem ser consideradas para que se possam atender aos seus objetivos institucionais, assegurar o alinhamento do modelo com a cultura e às orientações estratégicas, garantir flexibilidade diante de mudanças e estimular um ambiente de autodesenvolvimento, trabalho participativo e multifuncionalidade.

Nesse contexto, o Decreto $\mathrm{n}^{\circ} 5.707$ é considerado inovador pelos conceitos que utiliza, pois considera a capacitação como um processo permanente e deliberado de aprendizagem para o desenvolvimento de competências institucionais e individuais (AMARAL, 2008). Prevê, ainda, algumas ações: a divulgação e o gerenciamento das ações de capacitação, tais como: cursos presenciais e à distância, aprendizagem em serviços, grupos formais de estudos, intercâmbios, estágios, seminários e congressos (BRASIL, 2006).

Assim, um dos desafios é difundir a importância da gestão por competências para a capacitação, trabalhando o tema junto aos servidores de uma maneira geral, aos chefes de equipe e à área de recursos humanos. Cada servidor precisaria perceber aonde deseja ir profissionalmente, preocupando-se com seu desenvolvimento de modo articulado às estratégias organizacionais. Por esse caminho, a responsabilidade pela educação permanente seria assumida não apenas pelas escolas e setores de gestão de pessoas, mas compartilhada também pelos servidores (CORNACHIONI, 2010).

As organizações públicas precisam enfrentar mudanças para que um modelo de gestão de competência seja concretizado, e essas mudanças não devem ser somente da postura do servidor, mas principalmente da organização. Ela precisa criar condições para que o projeto saia do papel e para isso é necessário assessorar, medir resultados, ter um planejamento estratégico condizente com o projeto proposto. Para dar início a essa mudança na implantação do novo modelo acredita-se ser primeiramente necessário realizar o mapeamento das competências, conforme Carbone, Brandão e Leite (2005).

\subsection{Mapeamento de competências}

Nesta etapa há a descrição do procedimento de mapeamento de competências, segundo alguns autores (CARBONE; BRANDÃO; LEITE, 2005; BRANDÃO; 
GUIMARÃES; BORGES-ANDRADE, 2002); este segue melhor explanado nos aspectos metodológicos, item três.

O mapeamento de competências tem como propósito identificar o gap ou lacuna de competências, ou seja, a discrepância entre as competências necessárias para concretizar a estratégia corporativa e as competências internas existentes na organização. O passo inicial desse processo consiste em identificar as competências necessárias à consecução dos objetivos da organização. Para essa identificação, geralmente é realizada, primeiramente, uma pesquisa documental, que inclui a análise do conteúdo da missão, da visão de futuro, dos objetivos e de outros documentos relativos à estratégia organizacional (CARBONE; BRANDÃO; LEITE, 2005).

O questionário é talvez a técnica mais utilizada para mapear competências relevantes para um contexto organizacional. A formatação desse instrumento de pesquisa geralmente requer a aplicação prévia de uma ou mais das técnicas já relatadas (análise documental, observação e entrevista), com o objetivo de identificar elementos para compor os itens do questionário. Nesse caso, o pesquisador identifica, por intermédio de análise documental e/ou entrevistas, competências consideradas relevantes para a organização. Depois, ordena e descreve essas competências - que deverão compor os itens do questionário -, eliminando ambiguidades, duplicidades e irrelevâncias, conforme mencionado por Brandão, Guimarães e Borges-Andrade (2002).

A próxima etapa, segundo Carbone, Brandão e Leite (2005), consiste em definir a escala mais adequada para os respondentes do questionário avaliarem o grau de importância das competências; depois então, estabelecer o número de pontos, sendo recomendável a utilização de escalas com no mínimo 4 e no máximo 10 intervalos. É possível também utilizar uma escala comparativa, na qual se compara a importância de uma competência em relação à outra, ou, ainda, uma escala de ordenação, solicitando ao respondente que ordene as competências de acordo com a importância de cada uma, colocando, em primeiro lugar, a competência considerada mais importante e, em último, a menos importante.

É importante também incluir, ao final do questionário, uma seção destinada aos dados pessoais e profissionais do respondente, como idade, gênero, grau de escolaridade, formação, cargo exercido, tempo de trabalho na organização, dentre outros elementos relevantes. Tais dados permitem ao pesquisador identificar, por análises estatísticas, por exemplo, se o padrão das respostas dos participantes do sexo masculino difere do padrão das respostas atribuídas por participante do sexo feminino; permite saber, ainda, se pessoas com 
formação superior atribuem respostas diferentes às dos respondentes sem formação superior (CARBONE; BRANDÃO; LEITE, 2005).

Além da identificação das competências necessárias à estratégia organizacional, o mapeamento de competências pressupõe também inventariar as competências internas já disponíveis na organização, com o propósito de identificar a lacuna entre as competências necessárias e as já existentes na organização (CARBONE; BRANDÃO; LEITE, 2005).

Uma vez realizado o mapeamento da lacuna de competências, segundo Carbone, Brandão e Leite (2005), pode-se então planejar e realizar a captação e/ou o desenvolvimento de competências profissionais, visando minimizar essa lacuna, bem como retribuir os profissionais que manifestam, de forma exemplar, as competências necessárias à consecução dos objetivos organizacionais.

\section{Aspectos metodológicos}

O método de realização desta pesquisa foi o estudo de caso, utilizado quando se colocam questões do tipo "como" e "por que", quando o pesquisador tem pouco controle sobre os efeitos do fenômeno e quando o foco se encontra em questões contemporâneas, inseridas em algum contexto da vida real (BONOMA, 1985; YIN, 2001). O estudo de caso se caracteriza como um tipo de pesquisa cujo objeto é uma unidade que se analisa profundamente, visando ao exame detalhado de um ambiente, um determinado grupo social, um simples sujeito ou uma situação em particular (MERRIAM, 1988).

A abordagem da pesquisa classifica-se como qualitativa, uma vez que lida com interpretações das realidades sociais (BAUER; GASKELL, 2011), com características também quantitativas, já que se faz a descrição das frequências encontradas nos resultados obtidos, posteriores cálculos de média ponderada; e aplicada, quanto à natureza, uma vez que se tem a intenção de utilizar seus resultados na realidade (BARROS; LEHFELD, 2000).

Em relação aos objetivos, trata-se de uma pesquisa descritiva, já que busca descrever as características de determinado fenômeno sem ter a necessidade de explicá-lo (VERGARA, 2005). Os dados foram obtidos levando-se em consideração a perspectiva de seus participantes, sendo tais sujeitos da pesquisa os servidores ocupantes dos cargos de AA e de Chefes de Repartição, lotados na reitoria do IFTM. 


\subsection{A coleta e tratamento dos dados}

Primeiramente, com a finalidade de identificar os objetivos estratégicos da organização estudada, foram realizados levantamentos e análise de documentos relativos ao IFTM, em julho de 2012, baseando-se nos objetivos da unidade organizacional analisada, nas atribuições do cargo de AA, assim como outras informações ligadas às competências de seus servidores.

$\mathrm{Na}$ sequência, visando mapear as competências individuais requeridas ao exercício das atribuições do cargo e ao alcance dos objetivos estratégicos da organização, foram realizados dois grupos focais (TARAPANOFF, 1995; MORGAN, 1997), sendo um com 12 participantes, ocupantes do cargo de Chefe de Repartição, e o outro com 8 participantes, ocupando do cargo de AA, também em julho de 2012. As sessões de grupo focal tiveram a duração média de 60 minutos e nela os participantes foram numerados de R1 a R20, lembrando que até o R12 trata-se de Chefes de Repartição. Nas entrevistas foi abordada a seguinte questão: "Quais são as competências (conhecimentos, habilidades e atitudes) necessárias ao desempenho da função de AA na reitoria do IFTM?”. A análise do conteúdo foi feita em consonância com Bardin (1977).

Por fim, tendo-se por referência os elementos de competência que emergiram das falas dos servidores durante os grupos focais, foi elaborado um questionário (BORGESANDRADE; LIMA, 1983), o qual objetivou identificar tanto a importância atribuída, quanto o nível de domínio de cada uma das competências arroladas, na visão dos servidores.

O questionário foi validado com pequenas sugestões de melhoria, pelo método do juiz, conforme sugere Malhotra (2001). Este foi escolhido por pertencer ao meio acadêmico e ter experiência na aplicação dos conceitos da área de competências em pesquisas teóricas e estudos práticos. O questionário foi aplicado a todos os 32 servidores da reitoria do IFTM ocupantes do cargo de AA (procedimento de exaustão), no mês de agosto de 2012; destes, três servidores não responderam, por se encontrarem em período de férias, totalizando 29 respondentes. Posteriormente foi calculada a média de cada competência, com base na escala de Likert.

$\mathrm{Na}$ análise dos resultados, buscou-se identificar a relação entre os níveis de importância e de domínio atribuídos a cada competência, de modo a compreender quais competências eram consideradas essenciais e, dentre estas, as que eram tidas como deficitárias, apontando, assim, a necessidade de capacitação para o seu desenvolvimento. 


\section{Descrição e análise dos resultados}

Nesta etapa do trabalho há a consolidação de todos os dados levantados, seguida da análise dos mesmos, sendo esta precedida pela organização dos resultados encontrados.

\subsection{Caracterização da organização pesquisada e dos sujeitos da pesquisa}

O IFTM, criado em 29 de dezembro de 2008, pela Lei $\mathrm{n}^{\mathrm{o}} 11.892$, é uma Instituição de Educação Superior, Básica e Profissional, pluricurricular e multicampi, especializada na oferta de educação profissional e tecnológica nas diferentes modalidades de ensino, com base na conjugação de conhecimentos técnicos e tecnológicos com as suas práticas pedagógicas. No seu processo instituinte estão presentes na composição de sua estrutura organizacional uma reitoria localizada em Uberaba, o Centro Federal de Educação Tecnológica de Uberaba, a Escola Agrotécnica Federal de Uberlândia e as Unidades de Educação Descentralizadas de Paracatu e de Ituiutaba que, por força da Lei, passaram de forma automática, independentemente de qualquer formalidade, à condição de campus da nova instituição, passando a denominar-se respectivamente: Campus Uberaba, Campus Uberlândia, Campus Paracatu e Campus Ituiutaba. A reitoria é o órgão executivo do Instituto Federal, cabendo-lhe a administração, coordenação e supervisão de todas as atividades da autarquia (BRASIL, 2008).

O pessoal técnico-administrativo em educação do IFTM é constituído por servidores integrantes das carreiras de nível superior, médio e de apoio. Tem por atividades as relacionadas com a permanente manutenção e adequação do apoio técnico, administrativo e operacional necessário ao cumprimento dos objetivos institucionais, assim como as inerentes ao exercício de direção, chefia coordenação, assessoramento e assistência na própria instituição. A forma de ingresso obedece à legislação pertinente e acontece apenas por Concurso Público.

Atualmente a reitoria conta com 92 servidores, sendo 32 AAs, seis administradores, quatro analistas de TI, um assistente de alunos, um auxiliar de enfermagem, três contadores, um engenheiro civil, um engenheiro de segurança do trabalho, um motorista, oito pedagogos, um procurador, 20 professores (que ocupam função administrativa por meio de funções gratificadas ou cargos de direção), 12 técnicos de áreas diversas e um tecnólogo em cooperativismo. Dos AAs, totalizam 19 mulheres e 13 homens, dez possuem até 30 anos de idade, 14 entre 30 e 40 anos e oito acima dos 40 anos. 


\subsection{Os objetivos do IFTM e da reitoria e as atribuições do cargo de AA}

De acordo com o IFTM (2010) compete à reitoria:

a) A administração geral do IFTM, bem como a supervisão da execução das políticas de gestão educacional, de pessoas, orçamentária, financeira e patrimonial, visando ao aperfeiçoamento e à excelência das atividades de ensino, pesquisa e extensão;

b) elaborar, induzir, acompanhar e avaliar as políticas institucionais, bem como as propostas orçamentárias, e encaminhá-las para aprovação dos órgãos competentes;

c) planejar as estratégias de desenvolvimento do IFTM;

d) coordenar e supervisionar a execução dos planos aprovados, adotando medidas para seu cumprimento e avaliação dos resultados;

e) promover o relacionamento e o permanente intercâmbio com as instituições congêneres;

f) promover o planejamento, a integração e a cooperação mútua entre as unidades organizacionais que compõem o IFTM.

O Ministério da Educação, por intermédio do Ofício Circular $n^{\circ}$ 015/2005, (BRASIL, 2005) disponibilizou a descrição dos cargos técnico-administrativos em educação. Para o cargo de AA, o requisito para ingresso no cargo é a escolaridade, ou seja, ter concluído o ensino médio profissionalizante ou médio completo.

As atividades básicas do AA são: dar suporte administrativo e técnico nas áreas de recursos humanos, administração, finanças e logística; atender usuários, fornecendo e recebendo informações; tratar de documentos variados, cumprindo todo o procedimento necessário referente aos mesmos; preparar relatórios e planilhas; executar serviços nas áreas de escritório, assessorar nas atividades de ensino, pesquisa e extensão.

De acordo com o regimento geral e a descrição do cargo, pode-se entender que é necessário que ao AA possuir algumas competências para desempenhar sua função; estas são relacionadas aos conhecimentos em informática, redação oficial, legislação específica e atendimento ao público. 


\subsection{As competências consideradas importantes ao exercício do cargo de AA}

Nesta seção, primeiramente, discorre-se sobre as competências que emergiram dos relatos dos servidores entrevistados durante as seções de grupos focais. Na sequência, são apresentados os resultados relativos à aplicação do questionário.

No primeiro grupo focal houve a participação somente dos Chefes de Repartição; teve a finalidade de levantar as competências necessárias para que os AAs desempenhassem da melhor maneira possível suas funções dentro da reitoria, ou ainda quais seriam os conhecimentos, habilidades e atitudes essenciais, conforme Dutra et al. (2001) e Coelho e Fuerth (2009).

Por intermédio do gráfico representado na Figura 2, pode-se observar que os participantes foram unânimes ao defenderem que a "proatividade" é um fator fundamental. O "comprometimento" e a "motivação" também foram citados como relevantes, conforme salientado Affonso e Rocha (2010), e por Brandão (2007); este utilizou esta motivação para externar a capacidade de "querer fazer".

Foi perguntado qual seria o conhecimento mínimo ou básico que o AA deveria ter e eles responderam que seria a "informática", e que sem ela não seria possível fazer muita coisa, principalmente o Word e o Excel. Defenderam no geral o domínio da leitura e interpretação pelo fato de se trabalhar com muitos regulamentos.

A maioria dos participantes destacou a importância da vontade de aprender e do trabalho em equipe. Realizou-se outra pergunta sobre quais conhecimentos o grupo achava fundamentais para o AA, e a maioria respondeu que os conhecimentos exigidos no edital do concurso para o cargo de AA como redação oficial, leis e código de ética são muito importantes. Um participante rebateu dizendo: R12: "o problema do edital é a área que o assistente vai atuar e que tem coisas muito específicas de cada área, com atribuições diferentes”. E ainda acresce: R12: “é fundamental saber lidar com público e ter postura”. 
Figura 2 - Grau de importância das competências analisadas no questionário

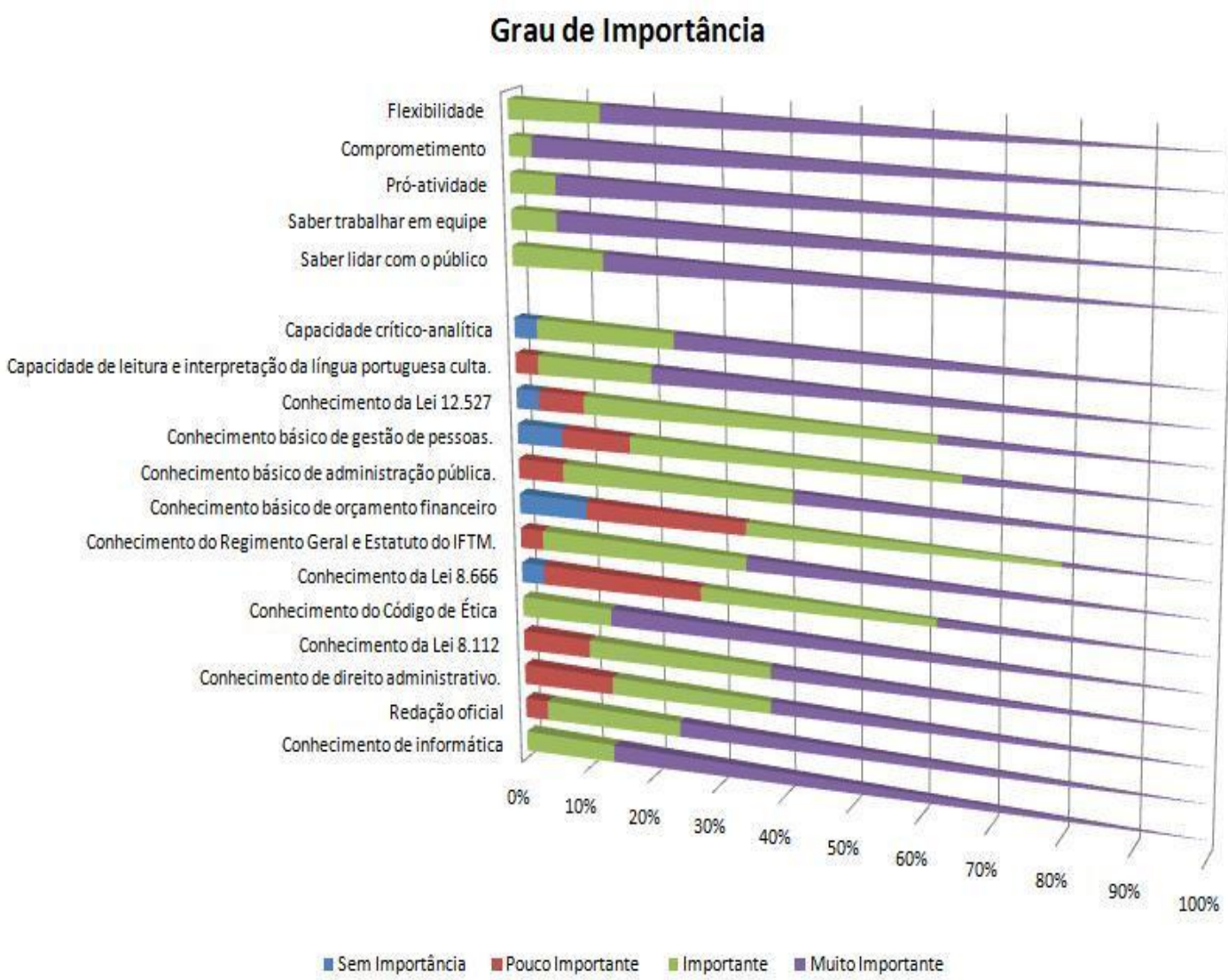

Fonte: Elaborada pelos autores.

Perguntou-se também sobre a necessidade de realização de curso de capacitação para adequar cada AA em sua função; quase todos os participantes disseram se tratar de uma tarefa de difícil de realização, e que seria mais adequado alguém do próprio setor para conduzir o novo AA. Outro ponto destacado foi sobre fazer uma análise do currículo pessoal para direcionar o AA ao setor que ele possui mais experiência, assim como relatado por Carbone, Brandão e Leite (2005). Todos os participantes afirmam ser necessários conhecimentos de modo geral.

Já o segundo grupo focal envolveu somente os AAs, principais atores do presente artigo. Foram trabalhadas as mesmas questões abordadas no primeiro grupo focal, onde cada um colocou sua opinião e concordaram com a maioria delas. Conforme um dos participantes: R19: “Os assistentes em administração por ser um trabalho mais geral e não específico, é necessário saber tudo de funcionamento administrativo, inclusive conhecimentos da área pedagógica". A totalidade dos participantes presentes concordou.

As importâncias de dominar a redação oficial e ter conhecimentos de informática, principalmente no que se refere ao pacote Office e Internet, também foram defendidas por todos. Pelo menos a metade ressalta a importância de ter noções gerais de direito 
administrativo, independente do setor, possuir conhecimentos sobre as leis de licitações e contratos e sobre as leis de responsabilidade fiscal. Um dos participantes acha necessário um plano de desenvolvimento institucional, e afirma que somente assim seria possível adequar melhor as competências para cada AA. Todos destacam a importância do desenvolvimento da comunicação entre setores.

No gráfico da Figura 3, percebe-se a opinião dos AAs no que diz respeito ao domínio necessário:

Figura 3 - Grau de domínio das competências analisadas no questionário

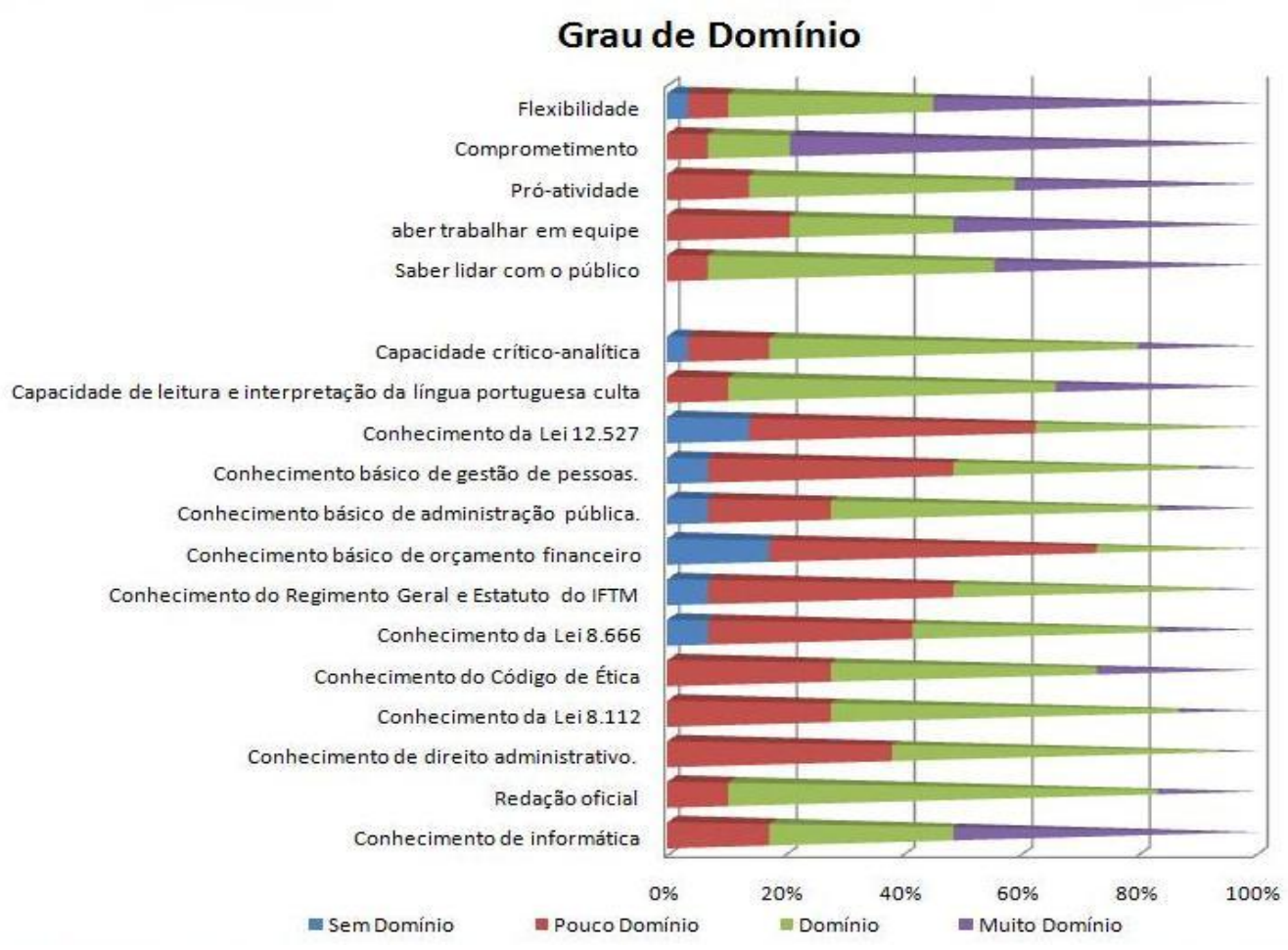

Fonte: Elaborada pelos autores.

Alguns participantes relataram que a exigência para a execução do trabalho é maior do que o exigido para o cargo; também destacam a necessidade de treinamento para adequar as habilidades (BRANDÃO; BORGES-ANDRADE, 2008), o que nem sempre acontece. A "proatividade" foi citada como uma das atitudes mais importantes, assim como o "atendimento ao público". Entre os participantes, todos defendem a "habilidade para trabalhar em equipe" e a "relação interpessoal". Estes dados foram de encontro aos levantados por Silva (2011); identificou-se "demonstrar ética", "otimizar contratação de pessoal”, "polidez" e "visão sistêmica" como principais atitudes dos servidores candidatos à chefes de gabinete do STJ; o que pode indicar a necessidade da administração pública realmente mapear as competências de cada cargo, de acordo com a sua realidade profissional. 
Foi relatado que o volume de trabalho é muito grande e que falta um planejamento para distribuir as competências de acordo com os conhecimentos, habilidades e atitudes de cada servidor, assim como treinamento adequado. Todos concordaram quanto aos conhecimentos que devem possuir e que há necessidade de treinamento para adequar as habilidades para o desempenho da função. Concordaram também sobre a importância do relacionamento interpessoal e domínio da estrutura organizacional para poder atender melhor ao público.

Pode-se observar com a análise dos dados que os dois grupos focais debateram sobre a necessidade de quase todas as competências, ou seja, falaram da importância dos conhecimentos, habilidades e atitudes que os AAs necessitam possuir para desempenhar com afinco as suas funções, assim como discutido por vários autores (CARBONE; BRANDÃO, LEITE, 2005; BRANDÃO; GUIMARÃES; BORGES-ANDRADE， 2002; COELHO; FUERTH, 2009). Entre os participantes, todos falaram da importância dos conhecimentos de informática, legislação e redação oficial. Foram unânimes em defenderem a "proatividade", o "trabalho em equipe" e o "conhecimento em relação ao atendimento do público".

Já em relação à aplicação dos questionários, na Tabela 1, são apresentados os resultados. Eles estão demonstrados em formato de média ponderada das notas atribuídas para cada competência:

Tabela 1 - Média das notas atribuídas por competência

\begin{tabular}{|c|c|c|}
\hline \multirow{2}{*}{ COMPETENCIAS } & \multicolumn{2}{|c|}{$\begin{array}{l}\text { MÉDIA DAS NOTAS ATRIBUÍDAS } \\
\text { PONTUAÇÃO: } 0 \text { A } 3 \\
\end{array}$} \\
\hline & IMPORTÂNCIA & DOMÍNIO \\
\hline Comprometimento & 2,96 & 2,72 \\
\hline Saber trabalhar em equipe & 2,93 & 2,31 \\
\hline Proatividade & 2,93 & 2,27 \\
\hline Flexibilidade & 2,86 & 2,41 \\
\hline Saber lidar com o público & 2,86 & 2,38 \\
\hline Conhecimento de informática (Word, Excel, Conectividade) & 2,86 & 2,34 \\
\hline Conhecimento do Código de Ética & 2,86 & 2,00 \\
\hline Capacidade de leitura e interpretação da língua portuguesa culta & 2,76 & 2,24 \\
\hline Redação oficial & 2,72 & 2,06 \\
\hline Capacidade crítico-analítica & 2,69 & 2,00 \\
\hline Conhecimento do Regimento Geral e Estatuto do IFTM & 2,62 & 1,51 \\
\hline Conhecimento da Lei 8.112 & 2,52 & 1,86 \\
\hline Conhecimento básico de administração pública & 2,52 & 1,83 \\
\hline Conhecimento de direito administrativo & 2,48 & 1,68 \\
\hline Conhecimento da Lei 12.527 & 2,24 & 1,27 \\
\hline Conhecimento básico de gestão de pessoas & 2,10 & 1,55 \\
\hline Conhecimento da Lei 8.666 & 2,07 & 1,68 \\
\hline Conhecimento básico de orçamento financeiro & 1,76 & 1,14 \\
\hline
\end{tabular}

Fonte: Elaborada pelos autores. 
Dentre as competências analisadas pelos AAs, apenas o conhecimento básico de orçamento-financeiro obteve nota entre 1 e 2, mostrando que este conhecimento tem pouca importância para as atividades desenvolvidas; dessa forma encontra-se em uma situação crítica, pois é considerada uma competência importante para os gestores e não tão importante para os AAs. Todas as outras competências obtiveram notas entre 2 e 3, mostrando que são de "importantes" a "muito importantes" para o desenvolvimento das atividades.

Quanto ao domínio, as competências que obtiveram menores notas são aquelas que necessitam de maior desenvolvimento, por capacitação geral ou treinamentos específicos. São elas: "conhecimento de direito administrativo", "conhecimento da legislação dos servidores públicos federais", da "legislação vinculada aos procedimentos licitatórios", "conhecimento do regimento geral e estatuto do IFTM", "conhecimento básico de orçamento financeiro", "conhecimento básico de administração pública" e "conhecimento básico de gestão de pessoas".

Percebe-se que a principal deficiência em domínio das competências está em conhecimentos básicos relacionados à gestão pública e legislação. As habilidades e atitudes são as competências que os AAs mais dominam, ênfase dada conforme Durand (2006). O "comprometimento" é a competência que é considerada pela maioria como importante e possui o maior grau de domínio. Sendo o "conhecimento do regimento geral e do estatuto do IFTM" a competência que possui a maior diferença entre a importância para as atividades desenvolvidas e o domínio que os AAs possuem.

\section{Considerações finais}

Este trabalho teve por objetivos identificar as competências do exercício do cargo de AA da reitoria do IFTM, proporcionando uma análise da consonância destas competências aos objetivos da organização e às atribuições do cargo, e consequentemente, analisar a viabilidade do uso da gestão por competências no IFTM. Para tanto, as pesquisas qualitativa e quantitativa foram realizadas, a fim de se medir os recursos de competência e os atributos associados à pessoa, tais como o conhecimento, as habilidades e as atitudes dos AAs, conhecidos como "CHA” (DUTRA et al., 2001; COELHO; FUERTH; 2009).

Assim, inicialmente, procurou-se fazer um levantamento sobre o tema gestão de competências e uma análise documental do regimento Interno e estatuto do IFTM (IFTM, 2009). Com foco nos objetivos propostos pelo trabalho, procurou-se por meio da realização de grupos focais e aplicação de questionários, descobrir quais as competências mais importantes 
na visão dos próprios servidores; da mesma forma, procurou-se identificar os gaps existentes nestas competências.

Dos grupos focais, extraíram-se dezoito competências relacionadas como "importantes" para o exercício do cargo de AA na reitoria do IFTM, sendo todas consideradas com "alto grau de importância" pelos próprios pesquisados, com exceção da competência "conhecimento básico de orçamento financeiro".

Após obtenção das médias de cada competência, com base na escala de Likert, e da identificação dos graus de domínio e importância atribuídos a cada uma delas pelos AAs, verificou-se a existência de lacunas de capacitação em oito competências, para as quais se sugere serem necessários treinamentos e qualificações.

Em termos gerais, pela análise dos dados apresentados, pode-se observar que houve grande convergência de opiniões entre os gestores e os AAs durante os debates dos grupos focais, sendo que ambos falaram da importância dos mesmos conhecimentos, habilidades e atitudes necessárias aos AAs, para o desempenho de suas funções; as principais competências listadas foram relativas aos conhecimentos de informática, legislação e redação oficial, além da unanimidade em defender a "proatividade", o "trabalho em equipe" e o "conhecimento do atendimento ao público".

Esta análise se fez importante em razão da necessidade patente da Administração Pública em atender a população com a melhor presteza possível. Desta forma, identificando talentos e alocando-os aos locais mais adequados aos seus perfis, aumenta-se a chance de "acerto" para ambos, instituição e servidor (PICCHIAI, 2011); assim, esta ação se consubstancia em algo que deve ser pensado e aprimorado pela Administração.

Em relação à gestão de competências, parece que se trata de um instrumento útil para auxiliar a reitoria do IFTM no atendimento das necessidades da sociedade, tendo como acréscimo o treinamento efetivo e constante, não se limitando aos AAs, mas também a todo o corpo técnico da reitoria, conforme Grando (2009).

Percebeu-se, também, que o desenvolvimento e a utilização das competências individuais (SANTOS, 2012; MUNCK; MUNCK; DE SOUZA; 2013) dos AAs podem fazer com que as ações de apoio e suporte das atividades desenvolvidas na reitoria sejam mais eficazes (GRANDO, 2009), contribuindo para o fortalecimento da imagem da reitoria do IFTM junto à sociedade e, junto a cada um dos campi.

Nesse contexto, o modelo utilizado mostrou-se eficaz no que diz respeito à discriminação de competências atuais e emergentes, pois permitiu descrevê-las em termos de 
comportamentos observáveis dos AAs da reitoria do IFTM, e permitiu identificar, ainda, sua essencialidade para o efetivo exercício do cargo (DUTRA et al., 2001).

Verificou-se, por fim, que o modelo aqui sugerido poderá contribuir para o fortalecimento das competências essenciais e capacidades da reitoria e para a melhoria da ação institucional e da imagem pública do IFTM. Esse modelo permitirá fortalecer as competências estáveis por meio de qualificação, eliminar as lacunas de competência por meio da capacitação e alavancar as competências emergentes, pela qualificação.

Assim, o modelo ora proposto, se adotado pela reitoria do IFTM, possibilitará o desenvolvimento de competências em todos os níveis da reitoria, para todos os diferentes setores, contrapondo as incertezas de aplicação deste modelo apontadas por Amaral (2008); dessa forma, trabalhar-se-á uma maneira lógica para que a instituição mantenha sua missão, amplie suas capacidades, valores e cultura organizacional, permitindo um alinhamento, de modo que todos estejam comprometidos a se mover na mesma direção, conforme salientado por Dutra, Hipólito e Silva (2000).

Espera-se que esta investigação tenha oferecido uma contribuição à organização, e que sirva de subsídio para a estratégia de captação, capacitação e desenvolvimento de todos os servidores. Espera-se que sirva, também, para a descrição de um perfil profissional ideal para a reitoria do IFTM em suas atividades de administração geral, bem como para a supervisão da execução das políticas de gestão educacional, de pessoas, orçamentária, financeira e patrimonial, visando ao aperfeiçoamento, ao desenvolvimento e à excelência das atividades de ensino, pesquisa e extensão, além de sugestão de treinamentos e cursos; dessa forma, este estudo contribuiu também para a sociedade. Espera-se, ainda, que tenha contribuído para a academia, referente aos estudos das funções, ações e cargos públicos, mais especificamente em relação às competências.

Sabe-se que este trabalho possui limitações; inicialmente cabe dizer que em grupos focais há a possibilidade de os respondentes não se exporem como talvez fizessem se fossem entrevistas individuais. Outra limitação diz respeito às possíveis falhas na interpretação das opiniões dos respondentes e a última a respeito da não possibilidade de generalização deste estudo às demais instituições.

Como pesquisas futuras se sugerem novas pesquisas no IFTM, desta vez com outros cargos, a fim de saber se os resultados encontrados se assemelham ou são contrários. Outro ponto que merece maior detalhamento seria a mesma pesquisa a ser realizada em outras instituições públicas possuidoras dos mesmos cargos, a fim de igualmente comparar os resultados. 


\section{REFERÊNCIAS}

AFFONSO, L. M. F.; ROCHA, H. M. Fatores organizacionais que geram insatisfação no servidor público e comprometem a qualidade dos serviços prestados. In: SEGeT - SIMPÓSIO DE EXCELÊNCIA EM GESTÃO E TECNOLOGIA, VII, 2010, Porto Alegre. Anais... Porto Alegre: [S.1.], p.1-15, 2010.

AMARAL, R. M. do. Gestão de pessoas por competências em organizações públicas. In: SEMINÁRIO NACIONAL DE BIBLIOTECAS UNIVERSITÁRIAS, XV, 2008, São Carlos. Anais... São Carlos: [S.1.], 2008, p. 875-898.

ARAÚJO, R. M. de L. Competência e qualificação: duas noções em confronto, duas perspectivas de formação dos trabalhadores em jogo. Trabalho \& Crítica, Fortaleza, n. 1, p. 173-186, 1999.

BARDIN, L. Análise de conteúdo. Lisboa: Edições 70, 1977.

BARROS, A. J. S.; LEHFELD, N. A. S. Fundamentos de metodologia: um guia para a iniciação científica. 2. ed. São Paulo: Makron Books, 2000.

BAUER, M. W.; GASKELL, G. (Orgs.). Pesquisa qualitativa com texto, imagem e som: um manual prático. 9. ed. Petrópolis: Vozes, 2011.

BONOMA, T. V. Case Research in Marketing: Opportunities, Problems, and a Process. Journal of Marketing Research, Georgia, v. 22, p. 199-208, 1985.

BORGES-ANDRADE, J. E.; LIMA, S. M. V. Avaliação de necessidades de treinamento: um método de análise de papel ocupacional. Tecnologia Educacional, Brasília, v. 13, n. 54, p. 6$22,1983$.

BRANDÃO, H. P. Competências no trabalho: uma análise da produção científica brasileira. Estudos de Psicologia, Brasília, v. 12, n. 2, p. 149-158, 2007.

BRANDÃO, H. P.; BORGES-ANDRADE, J. E. Causas e efeitos da expressão de competências no trabalho: para entender melhor a noção de competência. Revista de Administração Mackenzie, São Paulo, v. 8, n. 3, p. 32-49, 2008.

BRANDÃO, H. P.; GUIMARÃES, T. de A.; BORGES-ANDRADE, J. E. Competências profissionais relevantes à qualidade no atendimento bancário. Revista de Administração Pública, Rio de Janeiro, v. 35, n. 6, p. 61-81, 2002. 
BRASIL. Ministério da Educação. Secretaria Executiva. Subsecretaria de Assuntos Administrativos. Coordenação Geral de Gestão de Pessoas. Ofício Circular n⿳0 15 de 2005. Brasília, 2005.

BRASIL. Decreto $\mathbf{n}^{\mathbf{0}}$ 5.707, de 23 de Fevereiro de 2006. Disponível em: <http://www.planalto.gov.br/ccivil_03/_Ato2004-2006/2006/Decreto/D5707.htm>. Acesso em: 05 maio 2012.

BRASIL. Lei $\mathbf{n}^{\mathbf{1}}$ 11.892, de 29 de dezembro de 2008. Disponível em: <http://www.planalto.gov.br/ccivil_03/_ato2007-2010/2008/lei/111892.htm>. Acesso em: 04 jun. 2013.

CARBONE, P. P.; BRANDÃO, H. P.; LEITE, J. B. D. Gestão por competências e gestão do conhecimento. Rio de Janeiro: Fundação Getulio Vargas, 2005.

COELHO, M. P. C.; FUERTH, L. R. A influência da gestão por competência no desenvolvimento profissional. Revista Cadernos de Administração, [S.1.], v. 1, n. 3, p. 1-18, 2009.

CORNACHIONI, C. R. V. Perfil de competências do assistente em administração no desenvolvimento de suas atividades nas secretarias dos departamentos acadêmicos do Centro de Educação e Ciências Humanas da Universidade Federal de São Carlos (UFSCar). 2010. 58f. (Especialização em Gestão Pública) - Universidade Federal de São Carlos, São Carlos, 2010.

DURAND, T. L'alchimie de la compétence. Revue Française de Gestion, Paris, n. 1, p. 261292, 2006.

DUTRA, J. S. Gestão de Pessoas: modelos, processos, tendências e perspectivas. 1. ed. São Paulo: Atlas, 2002.

DUTRA, J. S. Competência: conceitos e instrumentos para a gestão de pessoas na empresa moderna. São Paulo: Atlas, 2008.

DUTRA, J. S.; HIPÓLITO, J. M. A.; SILVA, C. M. Gestão de pessoas por competências: o caso de uma empresa do setor de telecomunicações. Revista de Administração Contemporânea, Curitiba, v. 4, n. 1, p. 161-176, jan./mar. 2000.

DUTRA, J. S. et al. Gestão por competências: um modelo avançado para o gerenciamento de pessoas. 2. ed. São Paulo: Gente, 2001. 
FERNANDES, B. H. R.; FLEURY, M. T. Modelos de Gestão por competência: evolução e teste de um sistema. Revista Análise, Porto Alegre, v. 18, n. 2, p. 103-122, jul./dez. 2007.

FLEURY, A. C. C.; FLEURY, M. T. Estratégias empresariais e formação de competências: um quebra-cabeça caleidoscópico da indústria brasileira. São Paulo: Atlas, 2001.

FLEURY, A. C. C.; FLEURY, M. T. Estratégias empresariais e formação de competências. 3. ed. São Paulo: Atlas, 2004.

GILBERT, T. F. Human Competence: Engineering Worthy Performance. New York: McGraw-Hill Book Company, 1978.

GRANDO, J. O modelo gestão por competências na administração pública. 2009. 12f. (Especialização - MBA em Gestão de Recursos Humanos) - UNINTER, [S.1], 2009.

HAMEL, G.; PRAHALAD, C. K. The Core Competence of the Corporation. Harvard Business Review, Boston, v. 68, n. 3, p. 79-91, maio/jun. 1990.

IFTM. INSTITUTO FEDERAL DE EDUCAÇÃO, CIÊNCIA E TECNOLOGIA DO TRIÂNGULO MINEIRO. Regimento Geral. Uberaba, 2010.

IFTM. INSTITUTO FEDERAL DE EDUCAÇÃO, CIÊNCIA E TECNOLOGIA DO TRIÂNGULO MINEIRO. Resolução n ${ }^{\circ}$ 1, de 17 de agosto de 2009 - Aprova ad referendum, o Estatuto do Instituto Federal de Educação, Ciência e Tecnologia do Triângulo Mineiro. Diário Oficial da União, Brasília, 21 ago. 2009.

LE BOTERF, G. Desenvolvendo a competência dos profissionais. Porto Alegre: Artmed, 2003.

MALHOTRA, N. K. Pesquisa de marketing: uma orientação aplicada. Porto Alegre: Bookman, 2001.

MCCLELLAND, D. C. Testing for Competence Rather than for "Intelligence". American Psychologist,[S.1.], v. 28, n. 1, p. 1, 1973.

MERRIAM, S. B. Case Study Research in Education: a Qualitative Approach. San Francisco: Jossey Bass Publishers, 1988. 
MORGAN, D. Focus Group as Qualitative Research. Qualitative Research Methods Series. London: Sage Publications; 1997.

MUNCK, L.; MUNCK, M. G. M.; DE SOUZA, R. B. Avaliando modelos de competências a partir de um ciclo interligado de legitimação e validação qualitativa. Revista Alcance, Itajaí, v. 19, n. 4, p. 519-535, 2013.

PICCHIAI, D. Competências organizacionais, gerenciais e individuais: conceitos e discussões no setor Público. Revista da Micro e Pequena Empresa, Campo Limpo Paulista, v. 4, n. 3, p. 73-89, 2011.

PIRES, A. K. et al. Gestão por competências em organizações de governo. Brasília: ENAP, 2005.

ROTHWELL, W.; LINDHOLM, J. Competency Identification, Modeling and Assessment in the USA. International Journal of Training and Development, Oxford, v. 3, n. 2, p. 90105, Jun. 1999.

RUAS, R. L. Gestão por competências: uma contribuição à estratégia das organizações. In: RUAS, R. L.; ANTONELlO, C. S.; BOFF, L. H. Aprendizagem organizacional e competências: os novos horizontes da gestão. Porto Alegre: Bookman, 2005.

SANTOS, F. A. de S. dos. Articulação entre competências organizacionais e individuais em um Órgão do Poder Judiciário. 2012. 205f. Dissertação (Mestrado em Administração) Universidade de Brasília, Brasília, 2012.

SILVA, V. L. F. da. Identificação de competências individuais relevantes para o exercício do cargo de chefe de gabinete, no Superior Tribunal de Justiça. 2011. 47f. (Especialização em Gestão Judiciária) - Universidade de Brasília, Brasília, 2011.

SILVA, M. R. P. da. Análise das competências individuais requeridas pela sociedade do conhecimento: um estudo com alunos do curso de administração da Universidade Estadual da Paraíba. 2014. 57f. (Graduação em Administração) Campina Grande, 2014.

TARAPANOFF, K. (Org.) Inteligência organizacional e competitiva. Brasília: ed. Universidade de Brasília, 2001.

TARAPANOFF, K.; MIRANDA, D. M.; ARAÚJO JÚNIOR, R. H. de. Técnicas para a tomada de decisão nos sistemas de informação. Brasília: Thesaurus, 1995. 
VERGARA, S. C. Projetos e relatórios de pesquisa em administração. São Paulo: Atlas, 2005.

YIN, R. K. Estudo de caso: planejamento e métodos. 2. ed. Porto Alegre: Bookman, 2001.

ZARIFIAN, P. Objectif compétence. Paris: Liaisons, 1999.

ZARIFIAN, P. Objetivo competência: por uma nova lógica. São Paulo: Atlas, 2001. 